\title{
AS PESQUISAS DESENVOLVIDAS PELO GRUPO DE TRABALHO "DIFERENÇA, INCLUSÃO E EDUCAÇÃO MATEMÁTICA"
}

Reinaldo Feio Lima ${ }^{1}$

\begin{abstract}
Resumo: O Grupo de Trabalho 13 (GT 13), denominado Diferença, Inclusão e Educação Matemática, da Sociedade Brasileira de Educação Matemática (SBEM), é formado por pesquisadores preocupados com o desenvolvimento de uma Educação Matemática "para todos", na qual as particularidades associadas às práticas matemáticas dos diferentes aprendizes são valorizadas e entendidas. O objetivo deste artigo é identificar as pesquisas publicadas no I ENEMI relacionadas com práticas matemáticas mais acessíveis aos estudantes surdos, desenvolvendo uma pesquisa bibliográfica através dos procedimentos do Mapeamento na Pesquisa Educacional. Os resultados indicaram que o processo de mapeamento das pesquisas desenvolvidas pelo Grupo de Trabalho "Diferença, Inclusão e Educação Matemática" tem como foco central os estudos a respeito dos processos de ensino e de aprendizagem no/para estudantes, sejam na forma de intervenções pedagógicas ou produções de materiais didáticos.
\end{abstract}

Palavras-chave: Pesquisa. Prática Pedagógica. Educação matemática Inclusiva.

\section{Considerações iniciais}

Em 2013, foi criado o Grupo de Trabalho "Diferença, Inclusão e Educação Matemática" (GT 13), da Sociedade Brasileira de Educação Matemática (SBEM). Este grupo tem como objetivo agregar pesquisadores preocupados com o desenvolvimento de uma Educação Matemática "para todos", na qual as particularidades associadas às práticas matemáticas dos diferentes aprendizes são valorizadas e entendidas. Aborda pesquisas que buscam caminhos para uma cultura educacional que respeite a diversidade de aprendizes presente nos diferentes contextos educacionais, dentro e fora da escola. Contempla estudos que contribuem para uma compreensão profunda dos processos de ensino e de aprendizagem de Matemática, focando questões culturais, teóricas, metodológicas, pedagógicas e epistemológicas.

Nasce, assim, um termo denominado de Educação Matemática Inclusiva (EMI), como um "braço" da área de pesquisa Educação Matemática. Demarca um "novo" campo de estudos e pesquisas que atende e expressa o enfrentamento dos(as) professores(as) e pesquisadores(as) às questões epistemológicas, culturais, teóricas, metodológicas e pedagógicas, no contexto da escola, muito relacionadas com o campo do currículo (NEVES; PEIXOTO, 2019). Araújo (2011, p. 21) expressa muito bem esse enfrentamento, quando define a EMI como um novo campo, ainda em construção, cujo objetivo é facilitar:

[...] o acesso das pessoas com deficiência aos saberes matemáticos. Não estamos prontos, estamos sempre em fase de aprendizagem. Se nos depararmos com alunos com deficiência, somos pegos de surpresa com dúvidas sobre o que fazer. Qual o fazer docente nesta condição incomum? É

\footnotetext{
${ }^{1}$ reinaldo.lima@unifesspa.edu.br
} 
neste momento que, movido pelas angústias, o professor deve e tem obrigação de fazer com que o outro aprenda. Aí surgem as ideias de como fazer, criar, montar e adaptar para que o aluno, na condição de deficiência, aprenda. Isto é que é estar imerso no campo da Educação Matemática Inclusiva. É envolverse, é entender o outro como sujeito humano interessado pelo saber, é entender as suas limitações e propiciar adaptações para o acesso.

Araújo (2011) destaca a relevância de conhecer as limitações dos estudantes e a necessidade de desenvolver "[...] adaptações razoáveis para atender às características dos estudantes com deficiência e garantir o seu pleno acesso ao currículo em condições de igualdade, promovendo a conquista e o exercício de sua autonomia" (BRASIL, 2015, Cap. IV, Art. 28, Inciso III).

A nosso ver, os argumentos do autor limitam a abrangência desse campo ao atendimento das pessoas com deficiência e, consequentemente, não ampliam o debate para um ensino de matemática para todos. A expressão "matemática para todos" está plena de significado, pois apresenta implicitamente a ideia de que todos podem "aprender a matemática necessária para a vida presente e futura, como cidadãos críticos e ativos" (MARTINHO, 2016, p. 8). Nesses sentidos, as práticas pedagógicas inclusivas podem legitimar a exclusão dos estudantes nas instituições de ensino: muitos alunos estão passando "de uma situação de excluídos da escola para excluídos na escola" (VASCONCELOS, 2016, p. 40).

Essas discussões e preocupações desembocaram no ano de 2019, I Encontro Nacional de Educação Matemática Inclusiva (I ENEMI), que estava sob a coordenação de Clélia Ignatius (UEM), da Universidade Estadual de Maringá e vice-coordenação de Fernanda Malinosky (UFMS), da Universidade Federal do Mato Grosso do Sul. As preocupações deste GT incluem a discussão das práticas escolares e culturais, políticas educacionais, formação de professores, desempenho acadêmico e experiência com a matemática fora do contexto escolar de pessoas historicamente marginalizadas, em particular, pessoas:

$\checkmark$ com deficiências ou/e transtornos;

$\checkmark$ com altas habilidades;

$\checkmark$ com dificuldades específicas de aprendizagem de matemática;

$\checkmark$ em situação de risco ou vulnerabilidade social.

Em 2019, o GT13 teve 06 (seis) Mesas-Redondas, 05 (cinco) Grupos de Discussão (GD) e 08 (oito) Rodas de Conversa.

$\checkmark$ MR1 - Aspectos Teóricos e Práticos da Educação Matemática Especial e Inclusiva; 
$\checkmark$ MR2: Teorias de Sustentação para Pesquisas em Educação Matemática Especial e Inclusiva;

$\checkmark$ MR3: Contribuições das Escolas Especializadas para Educação Matemática Inclusiva;

$\checkmark$ MR4 - Atividades Potencialmente Inclusivas no Ensino de Matemática;

$\checkmark$ MR5: Formação de professores para a diversidade;

$\checkmark$ MR6: Educação Matemática e os Direitos Humanos para pessoas socialmente excluídas;

$\checkmark$ GD1. Surdez;

$\checkmark$ GD2. Aspectos Gerais da Educação Matemática Especial e Inclusiva;

$\checkmark$ GD3. Educação Matemática Inclusiva em instituições não escolares (idosos, vulneráveis, hospitalar etc.);

$\checkmark$ GD4. Deficiência Visual; GD5. Transtornos globais do desenvolvimento e deficiência intelectual;

$\checkmark$ RC1. Deficiência Visual;

$\checkmark$ RC2. Transtornos globais do desenvolvimento;

$\checkmark$ RC3. Educação Matemática Inclusiva: Educação do Campo e de Jovens e Adultos;

$\checkmark$ RC4. Educação Matemática Inclusiva: a formação docente;

$\checkmark$ RC5. Surdez;

$\checkmark$ RC6. Deficiência Intelectual;

$\checkmark$ RC7. Altas habilidades/ superdotação;

$\checkmark$ RC8. Diferença, Diversidade, inclusão e as (in)tolerâncias.

A partir dessas pontuações, verificamos que o contexto da Educação Matemática Inclusiva tem provocado nos pesquisadores do GT13 busca por investigação de novas configurações nos ambientes de ensino e de aprendizagem de pessoas historicamente marginalizadas, em particular, pessoas, por exemplo: com deficiências ou/e transtornos; com altas habilidades; com dificuldades específicas de aprendizagem de matemática; e em situação de risco ou vulnerabilidade social, com o intuito de ampliar perspectivas no ensino e reduzir barreiras na apropriação dos conhecimentos (NEVES; PEIXOTO, 2019).

Com o objetivo de identificar as pesquisas publicadas no I ENEMI relacionadas com práticas matemáticas mais acessíveis aos estudantes surdos, desenvolvemos uma pesquisa bibliográfica utilizando os procedimentos do Mapeamento na Pesquisa Educacional. Assim, foi 
possível identificar possíveis implicações para o campo da EMI. Na próxima seção, apresentaremos os procedimentos metodológicos utilizados para a busca das pesquisas e os resultados encontrados.

\section{Mapeamento dos trabalhos publicados no I ENEMI}

Para atender ao objetivo proposto, realizamos uma pesquisa bibliográfica (FIORENTINI; LORENZATO, 2006), utilizando como método o Mapeamento na Pesquisa Educacional (BIEMBENGUT, 2008). Para a autora, o mapeamento envolve:

Um conjunto de ações que começa com a identificação dos entes ou dados envolvidos com o problema a ser pesquisado, para, a seguir, levantar, classificar e organizar tais dados, de forma a tornarem mais aparentes as questões a serem avaliadas, reconhecer padrões, evidências, traços comuns ou peculiares, ou ainda características indicadoras de relações genéricas, tendo como referência o espaço geográfico, o tempo, a história, a cultura, os valores, as crenças e as ideias dos entes envolvidos - a análise .(BIEMBENGUT, 2008, p. 74).

Dessa forma, buscamos trabalhos nos anais do I ENEMI, ocorrido no ano de 2019, utilizando os seguintes descritores: surdo, educação de surdo e deficiência auditiva. Esta edição do I ENEMI está organizada com 74 artigos. Para a seleção dos trabalhos que seriam analisados, utilizamos alguns filtros (Quadro 1), de modo a tornar possível o levantamento de pesquisas com temáticas relevantes ao objetivo proposto.

Quadro 1: Filtros utilizados na seleção dos trabalhos analisados no IENEMI

\begin{tabular}{|c|c|}
\hline Tipo de Filtro & Especificação \\
\hline Tipo & Pesquisas publicadas nos anais do I ENEMI \\
\hline Ano & Ciências Humanas \\
\hline Grande área de conhecimento & Educação \\
\hline Área de conhecimento & $\begin{array}{c}\text { Educação, Educação Especial, Educação } \\
\text { Inclusiva, Educação Matemática Inclusiva }\end{array}$ \\
\hline No item “área de avaliação" & $\begin{array}{c}\text { Educação, Educação brasileira, Educação do } \\
\text { Indivíduo Especial, Ensino e Aprendizagem, } \\
\text { Formação de Educadores, Formação de } \\
\text { Professores, Práticas Educativas. }\end{array}$ \\
\hline Área de concentração & \\
\hline
\end{tabular}

Fonte: Elaborado pelo autor com base no trabalho de Neves e Peixoto (2019).

Ao final do mapeamento, e com os filtros devidamente aplicados, levantamos um total de 14 trabalhos. Em seguida, fizemos a leitura dos resumos e selecionamos apenas os trabalhos 
que tratam da Educação de Surdo e com relação na prática pedagógica na sala de aula envolvendo (ou não) estudantes com deficiência. Depois, sistematizamos esses resultados no Quadro 2, classificando-os em código.

Quadro 2: Trabalhos abordando a Educação de Surdo nos anais do I ENEMI.

\begin{tabular}{|c|c|c|c|c|c|}
\hline Código & Autor & Título & Instituição & Objetivo & Resultados \\
\hline T01 & $\begin{array}{l}\text { Kelvia Nunes da } \\
\text { SilvaWalber } \\
\text { Christiano Lima da } \\
\text { Costa }\end{array}$ & $\begin{array}{lr}\text { Construção } & \text { de } \\
\text { Materiais } & \\
\text { Pedagógicos para o } \\
\text { Ensino } & \text { de } \\
\text { Matemática } & \text { de } \\
\text { Alunos Surdos. } & \end{array}$ & UNIFESSPA & $\begin{array}{lr}\text { Construir materiais } \\
\text { pedagógicos } & \text { que } \\
\text { proporcionem } & \text { uma } \\
\text { aprendizagem } & \text { mais } \\
\text { adequada aos } & \text { surdos } \\
\text { no ensino } & \text { de } \\
\text { Matemática. }\end{array}$ & $\begin{array}{l}\text { Entregar os materiais } \\
\text { construídos ao Centro de } \\
\text { Atendimento Especializado } \\
\text { na área da Surdez-CAES, da } \\
\text { cidade de Marabá-PA, para } \\
\text { subsidiar a organização de } \\
\text { um Laboratório de materiais } \\
\text { didáticos para o ensino de } \\
\text { Matemática de alunos surdos. }\end{array}$ \\
\hline T02 & $\begin{array}{l}\text { Silene Pereira } \\
\text { Madalena } \\
\text { Caroline Lima de } \\
\text { Souza }\end{array}$ & $\begin{array}{l}\text { Estudantes surdos e a } \\
\text { construção da noção } \\
\text { de tempo: estratégias } \\
\text { de ensino em } \\
\text { contexto bilíngue } \\
\text { (Libras/Língua } \\
\text { Portuguesa). }\end{array}$ & $\begin{array}{l}\text { INES } \\
\text { UFRJ }\end{array}$ & $\begin{array}{l}\text { Apresentar } \\
\text { estratégias que visem } \\
\text { auxiliar na } \\
\text { construção da noção } \\
\text { de tempo de crianças } \\
\text { surdas, usuárias da } \\
\text { Língua Brasileira de } \\
\text { Sinais (Libras), do } \\
\text { Ensino Fundamental } \\
\text { de uma escola } \\
\text { bilíngue } \\
\text { (Libras/Língua } \\
\text { Portuguesa) do Rio } \\
\text { de Janeiro. }\end{array}$ & $\begin{array}{l}\text { Observou-se que a falta de } \\
\text { entendimento inicial das } \\
\text { crianças com relação à } \\
\text { compreensão dos marcadores } \\
\text { de tempo (dia, mês e ano) } \\
\text { ocorreu, principalmente, } \\
\text { pelas dificuldades } \\
\text { socioculturais que uma } \\
\text { criança surda enfrenta diante } \\
\text { de uma sociedade, } \\
\text { majoritariamente, ouvinte. } \\
\text { As experiências vividas } \\
\text { contribuíram para a } \\
\text { construção da noção de } \\
\text { tempo, tendo os alunos como } \\
\text { os principais atores de sua } \\
\text { aprendizagem. }\end{array}$ \\
\hline T03 & $\begin{array}{l}\text { Joseli Alves da } \\
\text { Silva }\end{array}$ & $\begin{array}{l}\text { Da teoria à prática: } \\
\text { uma experiência com } \\
\text { um licenciando } \\
\text { surdo. }\end{array}$ & UFRJ & $\begin{array}{l}\text { Objetivando } \\
\text { esclarecer possíveis } \\
\text { dúvidas de suas listas } \\
\text { de exercícios da } \\
\text { disciplina de Vetores. }\end{array}$ & $\begin{array}{l}\text { Esses momentos me } \\
\text { proporcionaram perceber que } \\
\text { não basta o uso de materiais } \\
\text { visuais e da Libras, há } \\
\text { necessidade } \\
\text { conhecimentos de estratégias } \\
\text { aliadas ao conteúdo } \\
\text { matemático para mediar a } \\
\text { aprendizagem. }\end{array}$ \\
\hline T04 & $\begin{array}{l}\text { Renata Gilaberte } \\
\text { Campos dos Santos } \\
\text { Júlio César dos } \\
\text { Santos Moreira }\end{array}$ & $\begin{array}{l}\text { Uma atividade } \\
\text { introdutória ao } \\
\text { conceito de função } \\
\text { para alunos surdos: } \\
\text { da concepção à } \\
\text { aplicação. }\end{array}$ & $\begin{array}{l}\text { UFRJ } \\
\text { INES }\end{array}$ & $\begin{array}{l}\text { Apresenta reflexões a } \\
\text { respeito } \\
\text { elaboração e da } \\
\text { resultados } \\
\text { aplicação de uma } \\
\text { atividade realizada } \\
\text { tendo como público- } \\
\text { alvo alunos surdos } \\
\text { inseridos em um } \\
\text { contexto de educação } \\
\text { bilíngue e tendo a } \\
\text { Libras como língua } \\
\text { de instrução. }\end{array}$ & $\begin{array}{l}\text { Acreditamos que a atividade } \\
\text { tenha sido realizada com } \\
\text { resultados positivos e que o } \\
\text { modelo utilizado tenha } \\
\text { propiciado aos alunos uma } \\
\text { compreensão completa do } \\
\text { problema apresentado. }\end{array}$ \\
\hline
\end{tabular}




\begin{tabular}{|c|c|c|c|c|c|}
\hline T05 & $\begin{array}{l}\text { Fabrícia } \\
\text { Nicomedes De } \\
\text { Souza } \\
\text { Jéssica Passos } \\
\text { Barreira } \\
\text { André Guimarães } \\
\text { Valente } \\
\text { Fernanda Paixão } \\
\text { de Souza Gouveia }\end{array}$ & $\begin{array}{l}\text { Uma Experiência } \\
\text { com Monitoria } \\
\text { Acadêmica de } \\
\text { Matemática para } \\
\text { Alunos Surdos no } \\
\text { PROEJA: } \\
\text { Expectativas e } \\
\text { Desafios em Um } \\
\text { Cenário de } \\
\text { Precarização. }\end{array}$ & IFRJ & $\begin{array}{l}\text { Apresenta um relato } \\
\text { de experiência que } \\
\text { expressa a construção } \\
\text { do conhecimento e } \\
\text { formação continuada } \\
\text { de profissionais } \\
\text { atentos às demandas } \\
\text { da população jovem e } \\
\text { adulta, em particular, } \\
\text { de sujeitos surdos do } \\
\text { Curso de Manutenção } \\
\text { e Suporte à } \\
\text { Informática, } \\
\text { integrado ao Ensino } \\
\text { Médio, do Campus } \\
\text { Duque de Caxias. }\end{array}$ & $\begin{array}{l}\text { Observamos um significativo } \\
\text { engajamento por parte das } \\
\text { alunas monitoras para que } \\
\text { houvesse um ambiente de } \\
\text { aprendizado efetivo para os } \\
\text { alunos surdos. A ausência de } \\
\text { intérprete de Libras nas } \\
\text { sessões de monitoria, como } \\
\text { também nas aulas regulares, e } \\
\text { a compreensível ausência de } \\
\text { proficiência na Língua } \\
\text { Brasileira de Sinais por parte } \\
\text { das monitoras não } \\
\text { possibilitaram que este } \\
\text { esforço gerasse resultados } \\
\text { práticos mensuráveis de curto } \\
\text { prazo, como um avanço } \\
\text { significativo no } \\
\text { conhecimentos matemáticos. }\end{array}$ \\
\hline T06 & $\begin{array}{l}\text { Cíntia de Fátima } \\
\text { Botelho } \\
\text { Rosana Maria } \\
\text { Mendes }\end{array}$ & $\begin{array}{l}\text { Surdez, Matemática } \\
\text { e Visualidade: uma } \\
\text { experiência com um } \\
\text { estudante surdo. }\end{array}$ & UFLA & $\begin{array}{lr}\text { Relatar } & \text { uma } \\
\text { experiência de ensino } \\
\text { e aprendizagem } & \text { que } \\
\text { envolveu r um } \\
\text { estudante r surdo } \\
\text { atendido pelo Centro } \\
\text { de Atendimento } \\
\text { Educacional } \\
\text { Especializado } \\
\text { (CAEE) de uma } \\
\text { cidade do sul de } \\
\text { Minas Gerais. }\end{array}$ & $\begin{array}{l}\text { Para finalizar esse trabalho, } \\
\text { gostaríamos de apontar que } \\
\text { essa experiência foi muito } \\
\text { importante para } \\
\text { constituição da nossa } \\
\text { identidade docente, afinal, o } \\
\text { contato com o estudante } \\
\text { surdo nos possibilitou } \\
\text { entender mais sobre a cultura } \\
\text { e a identidade surda. Esses } \\
\text { temas influenciam no } \\
\text { desenvolvimento } \\
\text { estudante do } \\
\text { consequentemente, nas } \\
\text { maneiras como os conteúdos } \\
\text { precisam ser abordados no } \\
\text { processo de ensino e } \\
\text { aprendizagem. }\end{array}$ \\
\hline T07 & $\begin{array}{l}\text { Rodrigo Carlos } \\
\text { Pinheiro }\end{array}$ & $\begin{array}{l}\text { Apropriação de } \\
\text { práticas de } \\
\text { numeramento por } \\
\text { estudantes jovens e } \\
\text { adultos surdos } \\
\text { bilíngues em um } \\
\text { curso de Educação } \\
\text { Financeira. }\end{array}$ & UFMG & 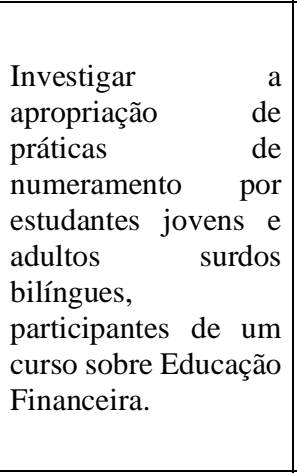 & $\begin{array}{l}\text { Aspira-se compreender os } \\
\text { sentidos da apropriação das } \\
\text { práticas de numeramento por } \\
\text { estudantes surdos, como } \\
\text { sujeitos pertencentes a uma } \\
\text { cultura própria (Cultura } \\
\text { Surda), dialogando com } \\
\text { estudos da etnomatemática, } \\
\text { do letramento, do } \\
\text { numeramento, da Educação } \\
\text { de Pessoas Jovens e Adultas } \\
\text { (EJA) e da educação de } \\
\text { surdos. }\end{array}$ \\
\hline T08 & $\begin{array}{l}\text { André Martins } \\
\text { Pinto Ferreira } \\
\text { Alves } \\
\text { Ágatha Cristina de } \\
\text { Almeida Santos } \\
\text { Marcelo Almeida } \\
\text { Bairral }\end{array}$ & $\begin{array}{l}\text { Vendando alunos } \\
\text { videntes para um } \\
\text { mergulho na } \\
\text { Matemática } \\
\text { Combinatória } \\
\text { Inclusiva. }\end{array}$ & UFRRJ & $\begin{array}{lr}\text { Aplicação } & \text { da } \\
\text { atividade lúdica sobre } \\
\text { Análise } \\
\text { Combinatória } \\
\text { Colégio no } & \text { Estadual } \\
\text { Presidente } & \text { Dutra, em } \\
\text { Seropédica, romo } \\
\text { avaliação } & \text { da } \\
\text { disciplina Ensino } & \text { de } \\
\text { Matemática } & \text { II } \\
\text { (IE/UFRRJ). }\end{array}$ & $\begin{array}{l}\text { O resultado obtido no final } \\
\text { das aulas foi muito } \\
\text { satisfatório, o retorno foi } \\
\text { altamente positivo. Os alunos } \\
\text { que participaram da atividade } \\
\text { nos dois dias não aprenderam } \\
\text { somenter análise } \\
\text { combinatória, mas também } \\
\text { um novo método de ensinar, } \\
\text { não só para alunos } \\
\text { videntes como para alunos } \\
\text { cegos também. }\end{array}$ \\
\hline
\end{tabular}




\begin{tabular}{|c|c|c|c|c|c|}
\hline T09 & $\begin{array}{l}\text { Janielli de Vargas } \\
\text { Fortes } \\
\text { Edmar Reis } \\
\text { Thiengo }\end{array}$ & $\begin{array}{l}\text { Do surdo para o } \\
\text { surdo: estratégias de } \\
\text { ensino e } \\
\text { aprendizagem da } \\
\text { Matemática. }\end{array}$ & IFES & \begin{tabular}{lr}
\multicolumn{2}{l}{ Discutir o ensino de } \\
Matemática & por \\
estudantes & surdos \\
para seus & colegas \\
surdos. &
\end{tabular} & $\begin{array}{l}\text { A discussão dos resultados } \\
\text { será distribuída em duas } \\
\text { grandes áreas: na Educação } \\
\text { Matemática, no que diz } \\
\text { respeito ao ensino e } \\
\text { aprendizagem } \\
\text { Matemática, e na Educação } \\
\text { de Surdos, no que diz respeito } \\
\text { aos sujeitos dessa pesquisa. E } \\
\text { como possibilidade de } \\
\text { produto educacional, a } \\
\text { produção de vídeos assistivos } \\
\text { que pode oferecer maiores } \\
\text { possibilidades a de } \\
\text { aprendizagem por estudantes } \\
\text { surdos. }\end{array}$ \\
\hline $\mathrm{T} 10$ & $\begin{array}{l}\text { Renata Vanessa } \\
\text { Souza Gonçalves } \\
\text { Pereira } \\
\text { Clélia Maria } \\
\text { Ignatius Nogueira } \\
\text { Fábio Alexandre } \\
\text { Borges }\end{array}$ & $\begin{array}{l}\text { Intersecções de } \\
\text { práticas pedagógicas } \\
\text { para surdos e } \\
\text { ouvintes no ensino } \\
\text { de Matemática: o } \\
\text { caso de uma } \\
\text { professora bilíngue. }\end{array}$ & $\begin{array}{l}\text { UNIOESTE } \\
\text { UNESPAR }\end{array}$ & $\begin{array}{l}\text { Identificar } r \text { se } \\
\text { existem intersecções } \\
\text { entre as práticas } \\
\text { docentes de uma } \\
\text { professora, fluente } \\
\text { em Libras, em suas } \\
\text { atuações na escola } \\
\text { bilíngue para surdos e } \\
\text { em uma escola } \\
\text { regular comum, a } \\
\text { exploração de formas } \\
\text { de comunicação não } \\
\text { verbal/linguagem } \\
\text { corporal e o recurso a } \\
\text { apoios visuais. }\end{array}$ & $\begin{array}{l}\text { A pesquisa busca } \\
\text { proporcionar reflexões sobre } \\
\text { a prática docente, quanto ao } \\
\text { ensino e à aprendizagem de } \\
\text { Matemática, no contexto de } \\
\text { uma sala de aula inclusiva. } \\
\text { Não temos a intenção de } \\
\text { desvalorizar o papel do } \\
\text { intérprete durante as aula de } \\
\text { matemática, mas buscamos } \\
\text { proporcionar uma melhor } \\
\text { comunicação e interação do } \\
\text { professor com todos os } \\
\text { alunos em sala de aula. }\end{array}$ \\
\hline $\mathrm{T} 11$ & $\begin{array}{l}\text { Jaqueline Ferreira } \\
\text { Cordeiro } \\
\text { Fernanda } \\
\text { Malinosky Coelho } \\
\text { da Rosa }\end{array}$ & $\begin{array}{l}\text { Uma análise sobre o } \\
\text { ensino e a } \\
\text { aprendizagem em } \\
\text { Lógica Matemática } \\
\text { de um aluno surdo no } \\
\text { Ensino Superior } \\
\text { público em Campo } \\
\text { Grande/MS. }\end{array}$ & UFMS & $\begin{array}{lr}\text { Como ocorre } & \text { o } \\
\text { processo de ensino e } & \\
\text { aprendizagem no } & \text { nnsino Superior de } \\
\text { um aluno surdo na } & \\
\text { disciplina de Lógica } \\
\text { Matemática. }\end{array}$ & $\begin{array}{l}\text { Espera-se que, além de } \\
\text { apontar possíveis avanços e } \\
\text { retrocessos no processo de } \\
\text { escolarização de um aluno } \\
\text { surdo na universidade em } \\
\text { questão, seja possível } \\
\text { contribuir para as pesquisas } \\
\text { relacionadas com a Educação } \\
\text { Especial, na perspectiva da } \\
\text { Educação Inclusiva no } \\
\text { Estado de Mato Grosso do } \\
\text { Sul e no âmbito nacional. }\end{array}$ \\
\hline $\mathrm{T} 12$ & $\begin{array}{l}\text { Nadjanara Ana } \\
\text { Basso Morás } \\
\text { Clélia Maria } \\
\text { Ignatius Nogueira }\end{array}$ & $\begin{array}{l}\text { Construção de tarefas } \\
\text { por meio da noção de } \\
\text { variáveis em um } \\
\text { modelo praxeológico } \\
\text { para inclusão de } \\
\text { alunos surdos. }\end{array}$ & UNIOESTE & $\begin{array}{l}\text { Analisar e identificar } \\
\text { quais } r \text { variáveis } \\
\text { podem gerar tarefas } \\
\text { que sejam capazes de } \\
\text { modificar as } \\
\text { praxeologias pessoais } \\
\text { dos estudantes surdos } \\
\text { em relação ao objeto } \\
\text { matemático, adição e } \\
\text { subtraçãorr com } \\
\text { números naturais, } \\
\text { levando-os, o mais } \\
\text { próximo possível, da } \\
\text { praxeologia } \\
\text { institucional. }\end{array}$ & $\begin{array}{l}\text { A partir dos resultados } \\
\text { encontrados } \\
\text { caracterizações, comparações } \\
\text { e análises das praxeologias } \\
\text { pessoais dos estudantes, } \\
\text { esperamos poder contribuir } \\
\text { para melhorar as práticas de } \\
\text { ensino de Matemática em um } \\
\text { contexto inclusivo no que diz } \\
\text { respeito ao objeto } \\
\text { matemático, adição e } \\
\text { subtração com números } \\
\text { naturais. }\end{array}$ \\
\hline
\end{tabular}




\begin{tabular}{|c|c|c|c|c|c|}
\hline $\mathrm{T} 13$ & $\begin{array}{l}\text { Francisca Melo } \\
\text { Agapito } \\
\text { Ieda Maria Giongo } \\
\text { Morgana } \\
\text { Domênica Hattge }\end{array}$ & $\begin{array}{l}\text { Alunos surdos e suas } \\
\text { multiplicações: } \\
\text { interlocuções com a } \\
\text { Etnomatemática. }\end{array}$ & $\begin{array}{c}\text { UFMA } \\
\text { UNIVATES }\end{array}$ & $\begin{array}{l}\text { Analisar as } \\
\text { matemáticas } \\
\text { produzidas por } \\
\text { alunos surdos do } 4^{\circ} \mathrm{e} \\
5^{\circ} \text { Anos do Ensino } \\
\text { Fundamental sobre } \\
\text { modos de operar com } \\
\text { a multiplicação. }\end{array}$ & $\begin{array}{l}\text { O escrutínio do material } \\
\text { mostrou que os discentes } \\
\text { surdos apresentam distintas } \\
\text { formas de realizar cálculos } \\
\text { com multiplicação, como } \\
\text { jogos de linguagem que } \\
\text { apresentam semelhanças e } \\
\text { diferenças com a Matemática } \\
\text { Escolar. }\end{array}$ \\
\hline $\mathrm{T} 14$ & $\begin{array}{l}\text { Rafael da Cunha } \\
\text { Braga } \\
\text { Edmar Reis } \\
\text { Thiengo } \\
\text { Thamires Belo de } \\
\text { Jesus }\end{array}$ & $\begin{array}{l}\text { Experiência de ser } \\
\text { surdo num curso de } \\
\text { Licenciatura em } \\
\text { Matemática: } \\
\text { entrelaçando olhares. }\end{array}$ & IFES & $\begin{array}{lr}\text { Descrever } & \text { o } \\
\text { entrelaçamento } & \text { de } \\
\text { olhares } & \text { da } \\
\text { experiência do } & \text { ser } \\
\text { surdo de } & \text { um } \\
\text { estudante num curso } \\
\text { de Licenciatura em } \\
\text { Matemática, hoje } \\
\text { professor } \\
\text { matemática de } \\
\text { Prefeitura Municipal } \\
\text { de Vila Velha-ES. }\end{array}$ & $\begin{array}{l}\text { Os resultados evidenciam } \\
\text { que, na atualidade, as } \\
\text { metodologias de ensino e } \\
\text { aprendizagem no campo da } \\
\text { Matemática continuam } \\
\text { voltadas para o ouvinte } \\
\text { (ditados, aulas expositivas, } \\
\text { resolução de problemas a } \\
\text { partir de textos escritos, } \\
\text { exercícios do livro sem } \\
\text { recurso visual). }\end{array}$ \\
\hline
\end{tabular}

Fonte: Elaborado pelo Autor (2020).

A análise seguiu os critérios do mapeamento, observando os aspectos: i) Autoria e origem dos trabalhos; ii) Objetivos ou questões norteadoras das pesquisas; ii) Aportes teóricos das pesquisas; iii) Metodologias utilizadas; iv) Principais resultados. A etapa seguinte foi “classificar e organizar tais dados, de forma a tornarem mais aparentes as questões a serem avaliadas, reconhecer padrões, evidências, traços comuns ou peculiares [...]”' (BIEMBENGUT, 2008, p. 74). Apoiados nesses critérios, apresentamos nossas impressões de cada pesquisa, para consideração pelo campo da Educação Matemática Inclusiva.

\section{Discussão dos resultados}

Fica evidente, no Quadro 2, uma questão interessante quanto à origem dos trabalhos que diz respeito à autoria. Os trabalhos publicados coletivamente, ou seja, aqueles que possuem mais de um autor correspondem a expressivos $85,71 \%$, sendo 50,00\% produzidos por dois autores (Quadro 2). Neste caso, podemos encontrar alguns trabalhos oriundos de iniciação científica, dissertações e teses, tendo, assim, assinatura do autor e seu orientador.

Identificamos, também, mapeamento dos trabalhos publicados segundo a modalidade de pesquisa (individual, em coautoria, em grupo, institucional, interinstitucional) e abrangência (local, estadual, nacional, internacional). Dois trabalhos são de autoria individual (14,29\%), sete trabalhos foram realizados em coautoria $(50,00 \%)$, dos quais três foram identificados como trabalhos que refletem pesquisas realizadas durante a iniciação científica, o doutorado e mestrado e, desta forma, a coautoria se deu entre orientador e orientando. Doze trabalhos foram realizados em grupo $(85,71 \%)$, dos quais conseguimos identificar que seis são referentes às investigações provenientes de grupos de pesquisas. Identificamos, também, que, em dez 
trabalhos $(71,43 \%)$, os autores pertencem a uma mesma instituição, enquanto quatro trabalhos (28,57\%) foram realizados de forma interinstitucional. Quanto à abrangência dos trabalhos, identificamos que os catorze trabalhos são de abrangência local e nacional, conforme podemos observar no Quadro 2.

No Quadro 2, estão mapeados 14 trabalhos publicados nos anais do I ENEMI vinculados a treze Instituições de Ensino Superior, nomeadamente: Universidade Federal do Sul e Sudeste do Pará - UUNIFESSPA, Universidade Federal do Rio de Janeiro - UFRJ, Universidade Federal Rural do Rio de Janeiro - UFRRJ, Instituto Federal do Rio de Janeiro - IFRJ, Instituto Nacional de Surdos - INES, Universidade Federal de Lavras - UFLA, Universidade Federal de Minas Gerais - UFMG, Instituto Federal do Espírito do Santo - IFES, Universidade Federal do Mato Grosso do Sul - UFMS, Universidade Federal do Maranhão - UFMA, Universidade Estadual do Oeste do Paraná - UNIOESTE, Universidade Estadual do Paraná - UNESPAR e Universidade do Vale do Taquari - UNIVATES.

Ao analisar os referenciais teóricos representadas pelos pesquisadores em suas investigações, destacam-se as Diretrizes Nacionais para Educação Especial na Educação Básica; Parâmetros Curriculares Nacionais; Base Nacional Curricular Comum; Educação de Surdos; Estratégias de Ensino/Pedagógicas com uso de materiais didáticos; Oficina de Matemática; Vygotsky; Ole Skovsmose; Etnomatemática; Práticas de numeramento; Análise Combinatória; Trabalho colaborativo.

Em relação ao delineamento metodológico representado nos trabalhos publicados no I ENEMI, verificamos que o viés qualitativo é predominante nos catorze textos. Do corpus analisado, dez assumiram o método qualitativo, o que representa $71,43 \%$ do total. Inferimos que tal resultado pode se justificar pelo fato de as áreas dos referidos programas - "Ensino" e “Educação" - valerem-se dessa modalidade de pesquisa (DE PAULA; CYRINO, 2017).

Essa abordagem metodológica (qualitativa) torna-se uma escolha plausível para a atividade de investigação nessas áreas, pois, no decorrer das atividades de coleta de dados, devido às características múltiplas do objeto de estudo, o pesquisador vê-se diante de uma gama de informações e apenas a análise quantitativa não lhe permite compreender o fenômeno (DE PAULA; CYRINO, 2017, p. 27.

No universo analisado, não foi encontrado trabalho que se assumisse como quantitativo. Em relação à natureza das pesquisas analisadas, conforme o Quadro 2, a maioria é empírica ou de campo (90,00\%), e apenas uma pesquisa, o T01, apresenta-se como uma produção de material didático (10,00\%). Além disso, observamos o cuidados do(s) autor(es) em explicitar o(s) objetivo(s), como podemos observar no Quadro 2, Coluna 5. Tais objetivos estão 
direcionados aos participantes de pesquisa, ou seja, dois trabalhos (T05 e T10) com foco no(a) professor(a) e os demais com foco no estudante.

A utilização de múltiplos instrumentos de produção de dados para a compreensão do fenômeno foi uma característica marcante no processo de análise das pesquisas desenvolvidas pelo GT13 da SBEM. Elas se valeram de instrumentos variados, em especial, aqueles que possibilitam, quando unificados, uma análise mais abrangente do fenômeno (DE PAULA; CYRINO, 2017). Como exemplo, podemos citar o uso de entrevistas, observação, questionários, vídeo-gravação e/ou áudio-gravação, pesquisa de campo, estudo de caso, empregados de modo conjunto.

Ao olharmos para o quadro de abrangência da pesquisa no que diz respeito aos resultados explicitados pelos autores dos catorze textos (Quadro 2, Coluna 6), vemos que todos os trabalhos apresentados no GT13 mencionaram os resultados alcançados ou esperados. Esses resultados estavam direcionados para a aprendizagem do estudante surdo no conteúdo de vetores (SILVA, 2019), conceito de função (SANTOS; MOREIRA, 2019), prática de numeramento (PINHEIRO, 2019), Análise Combinatória (ALVES; SANTOS; BAIRRAL, 2019), Lógica Matemática (CORDEIRO; ROSA, 2019), Noções de varáveis (MORÁS; NOGUEIRA, 2019) e Multiplicação (AGAPITO; GIONGO; HATTGE, 2019), e duas pesquisas com foco no professor: conhecimento e formação continuada de profissionais (SOUZA, et al., 2019) e práticas docentes de uma professora (PEREIRA; NOGUEIRA; BORGES, 2019).

\section{Considerações finais}

Pesquisas relativas ao campo de estudo "Diferença, Inclusão e Educação Matemática", da Sociedade Brasileira de Educação Matemática (SBEM), criado em 2013, vêm se ampliando nos últimos anos. Neste sentido, os pesquisadores que apresentaram seus trabalhos na primeira edição do Encontro Nacional de Educação Matemática Inclusiva estão distribuídos e atuando em diferentes regiões do Brasil, conforme se observa no Quadro 2.

De forma geral, no decorrer do processo de mapeamento das pesquisas desenvolvidas pelo Grupo de Trabalho "Diferença, Inclusão e Educação Matemática”, o foco central está nos estudos a respeito dos processos de ensino e de aprendizagem no/para estudantes, seja na forma de intervenções pedagógicas ou produções de materiais didáticos que apresentam objetivos e variadas temáticas investigativas (Quadro 2, Coluna 3 e 5). 
Em suma, pesquisas publicadas nos anais da I ENEMI com foco na Educação de Surdos, de caráter abrangente e nacional, são relevantes, tal como a executada no projeto nacional em diferentes Instituições de Ensino Superior, para o campo investigativo da Educação Matemática Inclusiva, que resultam em melhorias/mudanças metodológicas e contribuem qualitativamente para o desenvolvimento das discussões por partes dos membros do GT13 da SBEM, compreendendo que "as mudanças metodológicas no ensino de qualquer ciência dentro do contexto inclusivo, permeiam o que denominamos de adequações, adaptações ou flexibilizações curriculares" (ROQUEJANI, 2018, p. 32).

Por fim, salientamos que nossa intenção, com este mapeamento, é contribuir com os colaboradores do GT13 da SBEM, no sentido de melhor focarem e articularem aquilo que a área considere relevante que seja pesquisado na Educação Matemática Inclusiva e outras questões que venham ao encontro de sua busca, alavancando um avanço qualiquantitativo relativo às suas produções a partir do I ENEMI.

\section{Referências}

AGAPITO, F. M.; GIONGO, I. M.; HATTGE, M. D. Alunos surdos e suas multiplicações: interlocuções com a Etnomatemática. In: Anais do I Encontro Nacional de Educação Matemática Inclusiva. Rio de Janeiro: I ENEMI. Disponível em: < http://eventos.sbem.com.br/index.php/GT-13/ENEMI2019/schedConf/presentations >. Acesso em: 10 mai. 2019.

ALVES, A. M. P. F.; SANTOS, A. C. A.; BAIRRAL, M. A. Vendando alunos videntes para um mergulho na Matemática Combinatória Inclusiva. In: Anais do I Encontro Nacional de Educação Matemática Inclusiva. Rio de Janeiro: I ENEMI. Disponível em: < http://eventos.sbem.com.br/index.php/GT-13/ENEMI2019/schedConf/presentations>. Acesso em: 10 mai. 2019.

ARAÚJO, E. G. Intervenções de um professor de matemática cego. Dissertação (Mestrado em Educação para o Ensino de Ciências e Matemática) - Universidade Federal de Sergipe, Aracaju, 2011.

BIEMBENGUT, M. S. Mapeamento na pesquisa educacional. Rio de Janeiro: Editora Ciência Moderna, 2008.

BOTELHO, C. F.; MENDES, R. M. Surdez, Matemática e Visualidade: uma experiência com um estudante Surdo. In: Anais do I Encontro Nacional de Educação Matemática

Inclusiva. Rio de Janeiro: I ENEMI. Disponível em: < http://eventos.sbem.com.br/index.php/GT-13/ENEMI2019/schedConf/presentations >. Acesso em: 10 mai. 2019.

BRAGA, R. C.; THIENGO, E. R.; JESUS, T. B. Experiência de ser surdo num curso de Licenciatura em Matemática: entrelaçando olhares. In: Anais do I Encontro Nacional de Educação Matemática Inclusiva. Rio de Janeiro: I ENEMI. Disponível em: < 
http://eventos.sbem.com.br/index.php/GT-13/ENEMI2019/schedConf/presentations >. Acesso em: 10 mai. 2019.

BRASIL. Lei Brasileira da Inclusão no 13.146, de 6 de julho de 2015. Presidência da República, Casa Civil, Subchefia para Assuntos Jurídicos. Brasília, 2015. Disponível em: http://www.planalto.gov.br/ccivil_03/_Ato2015-2018/2015/Lei/L13146.htm. Acesso em: 16 mar. 2017.

CORDEIRO, J. F.; ROSA, F. M. C. Uma análise sobre o ensino e aprendizagem em lógica matemática de um aluno surdo no ensino superior público em Campo Grande/MS. In: Anais do I Encontro Nacional de Educação Matemática Inclusiva. Rio de Janeiro: I ENEMI. Disponível em: < http://eventos.sbem.com.br/index.php/GT13/ENEMI2019/schedConf/presentations >. Acesso em: 10 mai. 2019.

DE PAULA, E. F.; CYRINO, M. C. T. C. Mapeamento de pesquisas paranaenses sobre o professor que ensina matemática. RPEM, Campo Mourão, PR, v. 6, n. 11, p. 18-45, jul.-dez. 2017.

FIORENTINI, D.; LORENZATO, S. Investigação em educação matemática: percursos teóricos e metodológicos. Campinas: Autores Associados, 2006.

FORTES, J. V.; THIENGO, E. R. Do surdo para o surdo: estratégias de ensino e aprendizagem da matemática. In: Anais do I Encontro Nacional de Educação Matemática Inclusiva. Rio de Janeiro: I ENEMI. Disponível em: < http://eventos.sbem.com.br/index.php/GT-13/ENEMI2019/schedConf/presentations >. Acesso em: 10 mai. 2019.

MADALENA, S. P.; SOUZA, C. L. Estudantes surdos e a construção da noção de tempo: estratégias de ensino em contexto bilíngue (Libras/Língua Portuguesa). In: Anais do I Encontro Nacional de Educação Matemática Inclusiva. Rio de Janeiro: I ENEMI. Disponível em: < http://eventos.sbem.com.br/index.php/GT13/ENEMI2019/schedConf/presentations>. Acesso em: 10 mai. 2019.

MARTINHO, M. H. M. Prefácio. In: MANRIQUE, A. L.; MARANHÃO, M. C. S. A.; MOREIRA, G. E (org.). Desafios da educação matemática inclusiva: formação de professores. São Paulo: Editora Livraria da Física, 2016.

MORÁS, N. A. B.; NOGUEIRA, C. M. I. Construção de tarefas por meio da noção de variáveis em um modelo praxeológico para inclusão de alunos surdos. In: Anais do I Encontro Nacional de Educação Matemática Inclusiva. Rio de Janeiro: I ENEMI. Disponível em: < http://eventos.sbem.com.br/index.php/GT13/ENEMI2019/schedConf/presentations>. Acesso em: 10 mai. 2019.

NEVES, F. P. L; PEIXOTO, J. L. B. Abordagem Curricular do Desenho Universal para Aprendizagem: Implicações para a Educação Matemática Inclusiva. RPEM, Campo Mourão, Pr, v.8, n.17, p.320-345, jul.-dez. 2019.

PEREIRA, R. V. S. G.; NOGUEIRA, C. M. I.; BORGES, F. A. Intersecções de práticas pedagógicas para surdos e ouvintes no ensino de Matemática: o caso de uma professora bilíngue. In: Anais do I Encontro Nacional de Educação Matemática Inclusiva. Rio de 
Janeiro: I ENEMI. Disponível em: < http://eventos.sbem.com.br/index.php/GT13/ENEMI2019/schedConf/presentations>. Acesso em: 10 mai. 2019.

PINHEIRO, R. C. Apropriação de práticas de numeramento por estudantes jovens e adultos surdos bilíngues em um curso de educação financeira. In: Anais do I Encontro Nacional de Educação Matemática Inclusiva. Rio de Janeiro: I ENEMI. Disponível em: < http://eventos.sbem.com.br/index.php/GT-13/ENEMI2019/schedConf/presentations >. Acesso em: 10 mai. 2019.

ROQUEJANI, T. C. O ensino de geografia com adequações curriculares em salas inclusivas do ensino fundamental - anos finais. 2018. $214 \mathrm{f}$. Dissertação (Mestrado Profissional em Educação Básica) - Universidade Estadual Paulista Júlio de Mesquita Filho, Bauru, 2018.

SANTOS, R. G. C.; MOREIRA, J. C. S. Uma atividade introdutória ao conceito de função para alunos surdos: da concepção à aplicação. In: Anais do I Encontro Nacional de Educação Matemática Inclusiva. Rio de Janeiro: I ENEMI. Disponível em: < http://eventos.sbem.com.br/index.php/GT-13/ENEMI2019/schedConf/presentations>. Acesso em: 10 mai. 2019.

SILVA, J. A. Da teoria à prática: uma experiência com um licenciando surdo. In: Anais do I Encontro Nacional de Educação Matemática Inclusiva. Rio de Janeiro: I ENEMI.

Disponível em: < http://eventos.sbem.com.br/index.php/GT13/ENEMI2019/schedConf/presentations>. Acesso em: 10 mai. 2019.

SILVA, K. N. S.; COSTA, W. C. L. Construção de Materiais Pedagógicos para o Ensino de Matemática de Alunos Surdos. In: Anais do I Encontro Nacional de Educação

Matemática Inclusiva. Rio de Janeiro: I ENEMI. Disponível em: < http://eventos.sbem.com.br/index.php/GT-13/ENEMI2019/schedConf/presentations>. Acesso em: 10 mai. 2019.

SOUZA, F. N. et al. Uma Experiência com Monitoria Acadêmica de Matemática para Alunos Surdos no PROEJA: Expectativas e Desafios em Um Cenário de Precarização. In: Anais do I Encontro Nacional de Educação Matemática Inclusiva. Rio de Janeiro: I ENEMI.

Disponível em: < http://eventos.sbem.com.br/index.php/GT-

13/ENEMI2019/schedConf/presentations>. Acesso em: 10 mai. 2019.

VASCONCELOS, S. C. R. Educação Inclusiva no Brasil. In: MANRIQUE, A. L.; MARANHÃO, M. C. S. A.; MOREIRA, G. E (org.). Desafios da educação matemática inclusiva: formação de professores. São Paulo: Editora Livraria da Física, 2016. 